\title{
Agile HR Strategies: Prerequisite of Business Competitiveness in a Dynamic Environment
}

\author{
Audia Junita \\ \{audi.junita@gmail.com\} \\ Universitas Harapan Medan, Indonesia
}

\begin{abstract}
This article aims to analyze the domain of agile HR strategies that are oriented towards creating agile workers who play a strategic role in gaining and maintaining a sustainable competitive advantage of business in a rapidly changing market environment. Organizational agility is needed to be adaptive in responding to various dynamics of change in the business environment. The concept of agile organization applies to all forms of organization both manufacturing and services. Various domains of organizational agility studies in previous organizational studies. Literature review is used to analyze that problem. Organizations respond to changes in the business environment by utilizing the resources they have. How Agile HR strategies can leverage the dynamic dimensions of organizational agility (agile enablers), namely knowledgeable employees who have the agile capabilities for conduct learning, coordination, communication, and collaboration, are the main discussions of this article. Agile HR strategies include a set of policies and/or practices in the management of human resources in business organizations which, among others, can provide agile workers, collaborative work culture, learning organizations, design work-teams oriented, and practices oriented to empower workers. Managerial implications are presented at the end of this article.
\end{abstract}

Keywords: The Agile HR Strategies, Business Competitiveness, Dynamic

\section{Introduction}

The business environment changes dynamically in many forms. There are two important things related to the corporate environment, namely a very complex system and several components that are difficult to predict and respond to Haberberg and Rieple [1]. Each organization will interact with its environment [2] which has an uncertain and dynamic character [3] and consequently will be able to influence organizational activities. Globalization, developments in technology and information, increasingly fierce market competition, complex consumer needs, the emergence of virtual work teams and organizations, technology-based business processes, the involvement of various partners in business processes (collaboration), and various other forms of change.

Various changes in the environment require organizations to be agile in responding to various forms of change demands. Organizational agility is a strategy to stay adaptive and excel in competition in a fast-changing market environment. An agile organization is a condition for creating a work environment with members of the organization who are happy, have high involvement and creativity that can provide good value for the company as well as for customers [4]. 
The concept of organizational agility is important not only for business [5][6][7] but also for public organizations [8][9], including manufacturing companies [10][11] and services [12][13]. Various researchers in various forms of the organization prove that the characteristics of the capacity and capability of the organization's resources will greatly determine the level of organizational agility in responding to the demands of environmental change. Each organization in responding to its environment has different characteristics depending on the shape, nature, size, and culture of the organization as well as dynamic resources and capabilities.

Utilization and reconfiguration of various internal resources, efficient business processes, network and collaboration with partners, and the ability to adapt to technological advances are important in the process of increasing organizational agility [11]. Organizations need dynamic capabilities that are good enough as a competitive power against various environmental changes, both tangible and intangible, such as the strength of human resources and technology $[14][15]$.

Human assets are one of the internal resources of the organization that contribute to creating an agile organization because it is a dynamic dimension of organizational agility and functions as a driving force (agile enablers) [11]. By utilizing the knowledge of workers, the organization can increase its dynamic capabilities through sensing activities on market opportunities, learning to find new solutions by utilizing new knowledge, integrating various individual knowledge into new capabilities in one organizational operational unit, and coordinating all activities in an organization [16].

The characteristics of the agile worker required for an agile organization do not just appear. For the organization to have valuable internal resources and become an enabler for sustainable competitive excellence [17], it requires, among others, management actions including an intellectual agenda (shared mindset values), a behavioral agenda (cultural identity is translated into work behavior), and an agenda process (strengthening culture through management practices) [18]. This is in line with the resource-based theory which emphasizes that the source of organizational competitive advantage comes from the characteristics of the resources and capabilities that the organization has, including tangible and intangible resources [19], namely financial, physical resources, human and organizational assets (structures, systems, policies) that companies use to process and produce goods and/or services to customers [20]. An agile HR strategy is a strategic support subsystem in conditioning valuable human resources for an agile organization. An agility-oriented HR strategy has specific characteristics needed to develop an agile workforce [21][22][23]. This article focuses on analyzing agile HR strategies capable of creating agile workers. Business organizations will be agile if they have agile workers who are built with agile HR strategies who can create and provide added value for increasing business competitiveness in a dynamic environment.

\section{Methodology}

The method used to analyze the problem is a literature review that is carried out by collecting various literature, including books, magazines, articles, reports, journals, working papers, and other relevant supporting documents to strengthen analysis arguments in answering problems. 


\section{Discussion}

\subsection{Agile HR Strategy Architecture}

The human resource strategy architecture is an integration of the measurement of the organization's human resource function (HR function), human resource systems (HR systems), and employee strategic behaviors as shown in Figure 1 [24][25]. The strategic contribution of the human resource function of the organization is related to the ability to manage an infrastructure that can implement the organizational strategy while driving the strategic work behavior of organizational members. For this reason, the competence of human resource managers to carry out strategic functions and not just operational (technical) functions greatly affects organizational performance. Next, the dimensions of a high-performance human resource system include various policies/practices of organizational human capital management that can implement strategies while at the same time motivating workers to create value for the organization. In the end, the emergence of role behavior that is in line with the organizational strategic needs that are fundamental to an organization's competitive advantage. An agile HR strategy is the execution of a business strategy through the integration of the implementation of an agile HR function and system to shape the strategic behavior of agile workers as a condition that allows businesses to be adaptive to dynamic environmental changes.

\begin{tabular}{|l|}
\hline The HR Function \\
\hline $\begin{array}{l}\text { HR professional } \\
\text { with strategic } \\
\text { competencies }\end{array}$
\end{tabular}$\Rightarrow$\begin{tabular}{|l|}
\multicolumn{1}{|c|}{ The HR Systems } \\
\hline $\begin{array}{l}\text { High performance, } \\
\text { strategically aligned } \\
\text { policies and practices }\end{array}$
\end{tabular}$\Rightarrow$\begin{tabular}{l}
\multicolumn{1}{c|}{$\begin{array}{c}\text { Employee Strategic } \\
\text { Behavior }\end{array}$} \\
$\begin{array}{l}\text { Strategically focused } \\
\text { competencies, motivation, } \\
\text { and associated }\end{array}$ \\
\hline
\end{tabular}

Fig. 1. HR Strategy Architecture [25].

\subsection{The Shift in HR Functions in Business}

As the business environment changes dynamically, agile organizations always use enablers, capabilities, and various policies and practices to adapt to the changing demands of the environment [1]. The HR function is a strategic support subsystem to create value and competitive advantage in a sustainable manner [26].

The function of organizational human resource management has developed from time to time starting from a traditional (technical/operational orientation) [2][27] developing into a strategic orientation [28] in line with the development of human resource management theory. The HR function in today's business is no longer involved in carrying out technical/administrative activities. The strategic function of $\mathrm{HR}$ as a strategic business partner plays a role in aligning and executing various human resource management activities that are aligned with business strategy. For this reason, a set of professional human resource management competencies is needed that can meet the expectations of internal and external stakeholders and achieve business strategic value by managing talent, leadership, and culture that makes organizations have the capability to excel in the competition [29].

To respond to the demands of a very dynamic changing environment, the HR function in business is not only important as a strategic business partner through involvement in determining and executing business strategies, but also must be able to ensure the availability 
of a workforce that is agile in quantity and quality according to organizational needs. It takes HR specialists (core drivers) who are committed, have a leadership style and strategic planning that is visionary (strategic positioner) oriented to results and customers, skilled in communicating and collaborating (credible activist) with internal and external stakeholders, able to act as agents of change (cultural, and change champion), as well as mastering technology to respond quickly to various forms of change that will be socialized and carried out (technology and media integrator) oriented to create business value through various HR management policies and practices that are managed by the HR function [13][22][23][30].

\subsection{The Agile HR System}

The HR system is a series of human resource management policies or practices that are interconnected and directed to attract, develop, and maintain an organization's human resources [31]. The strength of human resource practices and policies as an HR system has a complementary nature beyond the strength of the sum of the effects of individual human resource practices and policies [32], therefore it is necessary to align one practice with another. Inconsistencies or conflicts between one practice and another in a human resource system will hurt the organization [33].

In an agile organization, it requires the characteristics of an HR system that can leverage the strategic behavior of agile workers. Agile HR systems include job design, staffing policies and practices, empowerment and participation, training and career development, performance appraisals, rewarding, and organizational communication patterns.

Agile job design is oriented towards teamwork and job enrichment [34]. Job enrichment allows flexibility through information sharing activities between colleagues so that vertical hierarchy can be minimized and provide opportunities for individuals to make decisions independently and have more authority in carrying out tasks in their way [35]. Organizations need to condition a collaborative work culture that is oriented towards developing worker learning capabilities.

Agile staffing policies and practices are what provide talent in business organizations. Talent is a workforce that has, commitment, competence, and a major contribution to the organization [36]. The existence of a lot of talent (talent pool) in the organization will make it easier for the organization to achieve its strategic goals in the long term as well as to anticipate the demands of environmental changes that require changing employee positions in the business [18]. A rigorous selection process with high-performance standards with an emphasis on the ability to make changes quickly and flexibly is an important indicator of business.

Furthermore, communication practices that are oriented towards developing worker competencies are needed to generate agile behavior. The use of a strong communication platform supports businesses to easily convey organizational cultural values, business strategies, and targets, as well as an agility model that the organization wants all organizational members to follow [13][21][23].

Participation and empowerment practices give workers the authority to make decisions and are empowered to oversee their work [37] so that employees can make situational decisions in completing work in a dynamic environment. The research results prove that the practice of empowering workers contributes significantly to increasing organizational agility [9].

Training and career development practices that give rise to agile workers are those that are oriented towards work team collaboration by utilizing technology-based learning media that allows various parties with various backgrounds and experiences to be actively involved 
so that trainees gain a lot of new knowledge along with problem-solving solutions including cross-organizational assignments to develop worker capabilities [22][23]. Businesses also need to condition themselves as learning organizations that facilitate members of the organization, both individuals and groups, even with external parties to share knowledge.

Performance appraisal practices that can leverage agile strategic behavior are those that are oriented towards developing potential future workers. The ability of employees to learn, adapt, and solve problems with various forms of change is an important point of assessment [22][23].

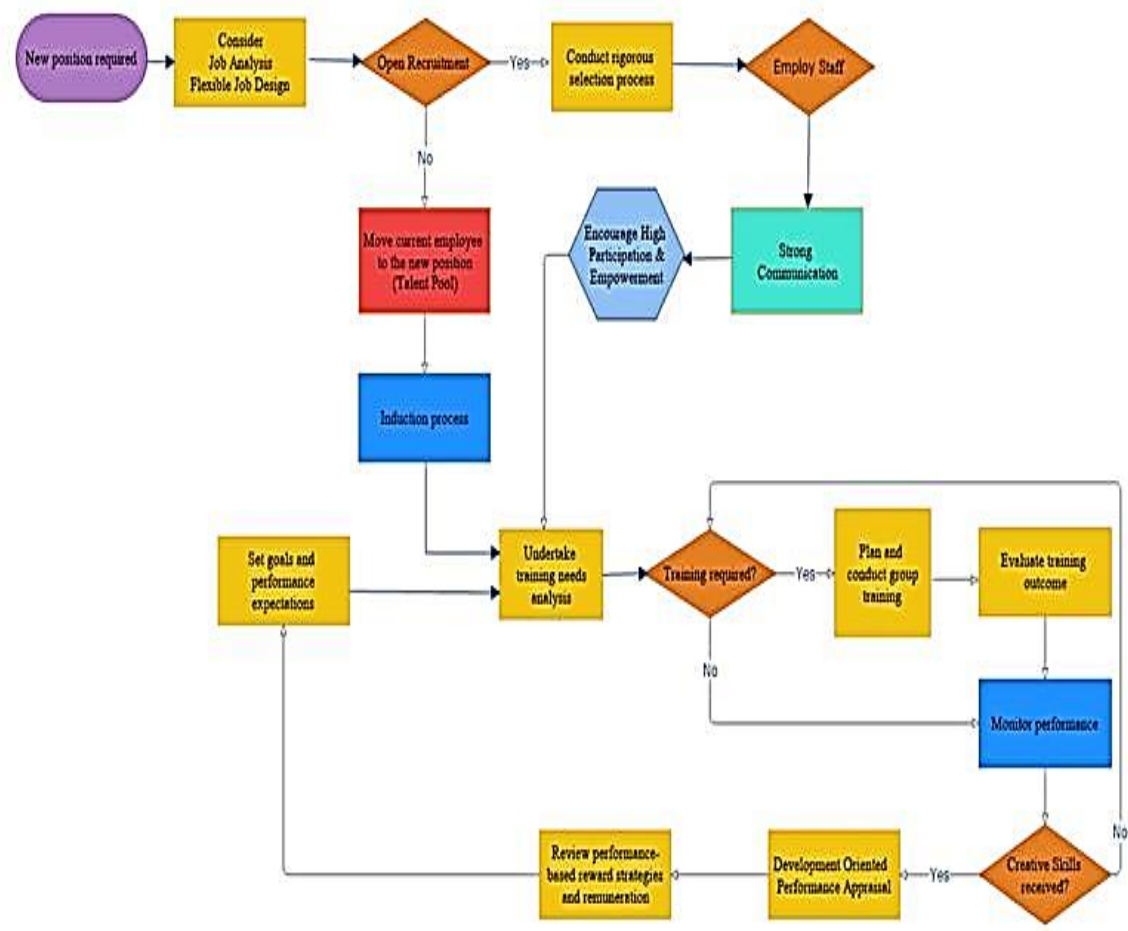

Fig. 2. The workflow of agile HR system.

Likewise, the distribution of rewards based on performance both individually and in groups, oriented to internal and external justice, which aims to reduce the wage gap between hierarchies can increase worker job satisfaction and build a competitive work culture [21]. Fair rewards will encourage employees to be more motivated and creative in completing their tasks. Agile HR system workflow takes place as shown in Figure 2.

\subsection{The Agile Strategic Behavior}

Work behavior is a strategic enabler that supports the creation of an agile organization. Wise and Daniel [38] support this statement. But the agile behavior of the workers did not just show up. Behavior is a form of response from satisfaction or dissatisfaction with various policies or practices of the organization's human resource management. Human resource management activities are the primary means for organizations to transmit role information, support desired behavior, and assess role performance. Delivery of role information will be 
effective if role expectations are consistently communicated within the organization and assess performance in ways that are consistent with organizational contingency factors, including business strategy. Effective human resource management helps meet expectations of colleagues in carrying out roles within the organization (including supervisors, colleagues, subordinates) and parties outside the organization involved (including consumers, families, communities). The behavioral expectations of all parties with an interest in the role will influence the role behavior of each member of the organization [39].

Table 1. The Differences between agile and non-agile HR

\begin{tabular}{|c|c|c|c|}
\hline Sis. & 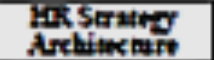 & NomAgle IR & Agh KaR \\
\hline I & Fister & 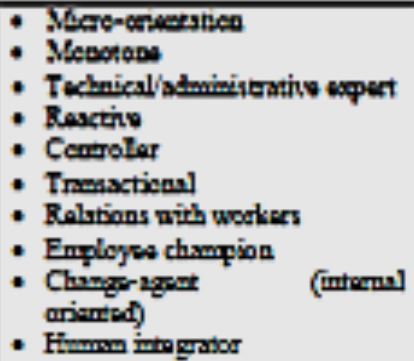 & 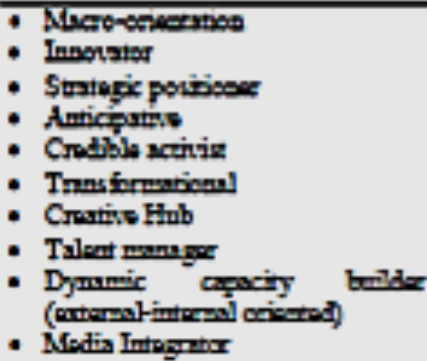 \\
\hline 2 & The HR System & 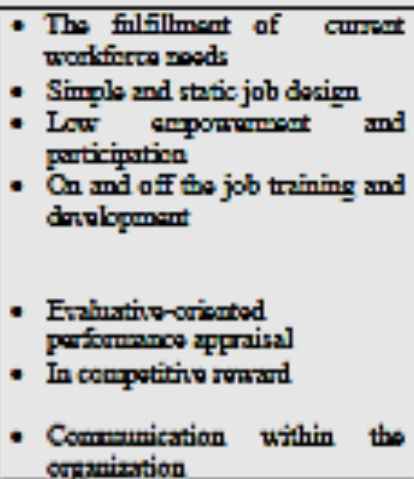 & 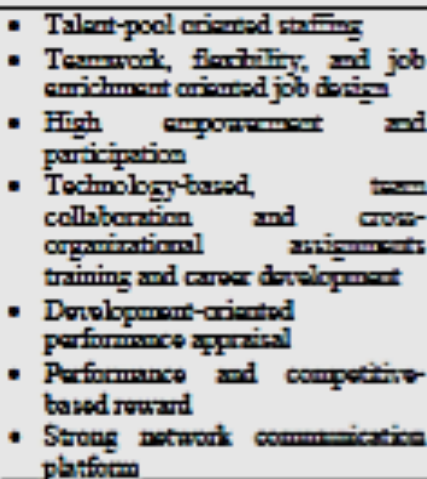 \\
\hline 3. & 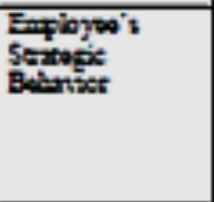 & 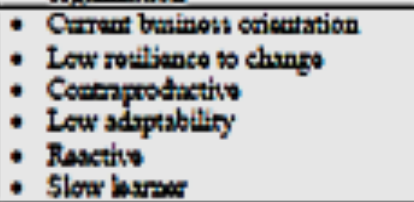 & 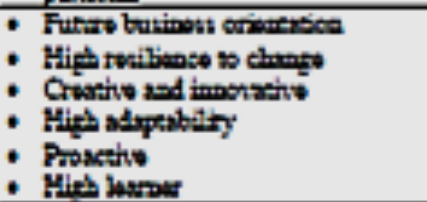 \\
\hline
\end{tabular}

Some of the behavioral characteristics of an agile workforce include: (1) business orientation, namely conforming to business values, mastering knowledge of business operations, the environment, and future business priorities; (2) has high resilience over various forms of change, new ideas, technology and is tolerant of uncertain situations; (3) High adaptability to people, culture, duties, and responsibilities; (4) be proactive in anticipating various problems that may arise as a result of change; (4) self-awareness to always want to learn and develop themselves, adjusting to changes in the business environment [2][22]. A summary of the comparison of the agile and non-agile human resource strategies can be seen in Table 1. 


\section{Conclusion}

An agile HR strategy is a prerequisite for a sustainable business competitive advantage in a dynamic environment. An agile HR strategy includes the implementation of an agile HR function and system that can leverage the emergence of workers who have agile work behaviors in dynamic environments. Agile HR strategies include a set of policies and/or practices in the management of human resources in business organizations which, among others, can provide agile workers, collaborative work culture, learning organizations, design work-teams oriented, and practices oriented to empower workers which are integrated as an HR system. Important managerial implications for business are important to strengthen HR functions and systems to generate a workforce with agile behavior as a prerequisite for agile business in a dynamic environment.

\section{References}

[1] A. Haberberg and A. Rieple, Strategic management: Theory and application. Oxford University Press, 2008.

[2] H. M. Jo, "Organization Theory: Modernsymbolic and Postmodern Perspectives." Oxford University Press, 1997.

[3] G. R. Jones, Organizational theory: Text and cases. Prentice Hall, 2001.

[4] T. Grant, "Agile in the real world: Gone mainstream, creating bigger waves, making course corrections." 2013.

[5] A. T. Kharabe, "Organizational agility and complex enterprise system innovations: A mixed methods study of the effects of enterprise systems on organizational agility." Case Western Reserve University, 2012.

[6] M. Dubey, "Evolving Business Excellence Framework for Organization agility," 2014.

[7] Y. Park, O. A. El Sawy, and P. Fiss, "The role of business intelligence and communication technologies in organizational agility: a configurational approach,” J. Assoc. Inf. Syst., vol. 18, no. 9 , p. 1,2017 .

[8] W. Cellary and W. Picard, "Agile and pro-active public administration as a collaborative networked organization," in Proceedings of the 4th International Conference on Theory and Practice of Electronic Governance, 2010, pp. 9-14.

[9] B. Asgarnezhad Nouri and M. Mir Mousavi, "Effect of cooperative management on organizational agility with the mediating role of employee empowerment in public transportation sector," 2020.

[10] A. Gunasekaran, Agile manufacturing: the 21st century competitive strategy. Elsevier, 2001.

[11] R. Žitkienè and M. Deksnys, "Organizational agility conceptual model," 2018.

[12] J. C. Miller, Service agility: A crucial component of service strategy. Michigan State University, 2010

[13] A.-C. Fernstrom, "A Framework for Changing Organizational Culture for Agile Transformations: A Delphi Study." University of Phoenix, 2019.

[14] D. J. Teece, G. Pisano, and A. Shuen, "Dynamic capabilities and strategic management," Strateg. Manag. J., vol. 18, no. 7, pp. 509-533, 1997.

[15] D. J. Teece, Dynamic capabilities and strategic management: Organizing for innovation and growth. Oxford University Press on Demand, 2009.

[16] P. A. Pavlou and O. A. El Sawy, "Understanding the elusive black box of dynamic capabilities," Decis. Sci., vol. 42, no. 1, pp. 239-273, 2011.

[17] J. Barney, "Firm resources and sustained competitive advantage," J. Manage., vol. 17, no. 1, pp. 99-120, 1991.

[18] D. Ulrich, "From war for talent to victory through organization," Strateg. HR Rev., 2015.

[19] R. M. Grant, "The resource-based theory of competitive advantage: implications for strategy 
formulation," Calif. Manage. Rev., vol. 33, no. 3, pp. 114-135, 1991.

[20] J. B. Barney, "Looking inside for competitive advantage," Acad. Manag. Perspect., vol. 9, no. 4, pp. 49-61, 1995.

[21] A. Muduli, "Workforce Agility: A Review of Literature.," IUP J. Manag. Res., vol. 12, no. 3, 2013.

[22] A. V. Azuara, "A human resource perspective on the development of workforce agility." Pepperdine University, 2015.

[23] P. Lee, "A study of human resources practices within agile organizations." Pepperdine University, 2015.

[24] R. W. Beatty, M. A. Huselid, and C. E. Schneier, "New HR Metrics:: Scoring on the Business Scorecard," Organ. Dyn., vol. 32, no. 2, pp. 107-121, 2003.

[25] B. E. Becker, M. A. Huselid, M. A. Huselid, and D. Ulrich, The HR scorecard: Linking people, strategy, and performance. Harvard Business Press, 2001.

[26] J. B. Barney and D. N. Clark, Resource-based theory: Creating and sustaining competitive advantage. Oxford University Press on Demand, 2007.

[27] J. M. Shafritz and J. S. Ott, "Classics of organization theory Fifth Ed." Harcourt, New York, NY, USA, 2001.

[28] D. Ulrich, "Human Resource Champions: The next agenda for adding value and delivering results. 1997." Boston, Massachusetts: Harvard Business School Press.

[29] M. G. Sai and M. R. Sayee, "Victory through organization: Why the war for talent is failing your company and what you can do about it by Dave Ulrich, David Kryscynski, Mike Ulrich, Wayne Brockbank," J. Values-Based Leadersh., vol. 11, no. 1, p. 14, 2018.

[30] N. Bushey, "Enhancing organizational agility within the human resources function," 2019.

[31] A. A. Lado and M. C. Wilson, "Human resource systems and sustained competitive advantage: A competency-based perspective," Acad. Manag. Rev., vol. 19, no. 4, pp. 699-727, 1994.

[32] D. Alewell and N. K. Hansen, "Human resource management systems - a structured review of research contributions and open questions," Ind. Beziehungen/The Ger. J. Ind. Relations, pp. 90-123, 2012.

[33] M. F. Spratt, "Hp as a Source (of Shareholder Value: Research and Recommendations," Hum. Resour. Manage., vol. 36, no. 1, pp. 39-47, 1997.

[34] E. E. Lawler III, "Choosing an involvement strategy," Acad. Manag. Perspect., vol. 2, no. 3, pp. 197-204, 1988.

[35] K. Kwon, J. Bae, and J. J. Lawler, "High commitment HR practices and top performers," Manag. Int. Rev., vol. 50, no. 1, pp. 57-80, 2010.

[36] D. Ulrich, "The talent trifecta," Dev. Learn. Organ. An Int. J., 2008.

[37] J. Pfeffer, "Seven practices of successful organizations," Calif. Manage. Rev., vol. 40, no. 2, p. 97, 1998.

[38] T. P. Wise and R. Daniel, Agile readiness: Four Spheres of lean and agile transformation. Gower Publishing, Ltd., 2015.

[39] S. E. Jackson and R. S. Schuler, "Understanding human resource management in the context of organizations and their environments," Annu. Rev. Psychol., vol. 46, no. 1, pp. 237-264, 1995. 